\title{
Fracture Modes of AISI Type 302 Stainless Steel Under Metastable Plastic Deformation
}

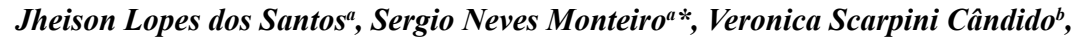 \\ Anderson Oliveira da Silva ${ }^{a}$, Flavio James Tommasini ${ }^{a}$ \\ a Departamento de Ciência dos Materiais, Instituto Militar de Engenharia - IME, Praça Geral Tibúrcio, \\ 80, Praia Vermelha, CEP 22290-270, Rio de Janeiro, RJ, Brazil \\ ${ }^{b}$ Faculdade de Engenharia de Materiais, Universidade Federal do Pará - UFPA, Campus de \\ Ananindeua, BR 316, Km 7, n 590, CEP 67113-901, Ananindeua, PA, Brazil
}

Received: January 17, 2017; Accepted: October 11, 2017

\begin{abstract}
Martensitic transformation can be induced by plastic deformation in metastable iron-based alloys, such as stainless steels containing limited amounts of $\mathrm{C}, \mathrm{Ni}$ and $\mathrm{Cr}$. This transformation takes place at the temperature range from $\mathrm{M}_{\mathrm{s}}$ and $\mathrm{M}_{\mathrm{d}}$, usually at relatively lower temperature values. The transformed martensite has been associated with maximum ultimate strength and relatively high ductility. In the present work, the tensile fracture characteristics of a metastable AISI type 302 stainless steel was investigated in the range of temperatures from $-196^{\circ} \mathrm{C}$ to $25^{\circ} \mathrm{C}$. Mechanical properties were compared to those of a stable AISI type 310 austenitic stainless steel. It was found that in 302 steel, its high degree of metastability and dilute dispersion of inclusions result in higher strength and complex modes of fracture, one of which consisting of martensite surrounding globular inclusions.
\end{abstract}

Keywords: AISI type 302 stainless steel, metastable deformation, martensitic transformation, fracture modes

\section{Introduction}

Steels exhibiting higher strength usually display lower ductility except when martensite transformation occurs during plastic transformation ${ }^{1}$. Indeed, high ductility was earlier found to be associated with improved strength in metastable steels, such as TRIP ${ }^{2-5}$, high chromium ${ }^{6}$ and stainless ${ }^{7,8}$ undergoing strain-induced martensitic transformation.

By that time, the effect of martensitic deformation on the fracture of tensile deformed TRIP steels was reported by Maxwell ${ }^{9}$. In high nickel TRIP steel with varying carbon content, Maxwell ${ }^{9}$ found that failure was strongly dependent on the presence of both strain-induced and stress-associated martensite. He suggested that the mechanisms of failure were: cleavage across the stress-assisted martensite plates and decohesion at the austenite/strain-induced martensite, with subsequent voids formation leading to crack nucleation. Maxwell ${ }^{9}$ also proposed that dispersed carbides in TRIP steels would initiate strain-induced martensite. Subsequently, voids might be formed at these carbide/martensite sites and so preventing the intergranular fracture observed when martensite initiates at grain boundaries.

As for stainless steels, Bressanelli and Moskowitz ${ }^{7}$ suggested that the amount of martensite formed during necking in AISI 316 steel would enhance ductility. On the contrary Rosen et al. ${ }^{8}$ argued that it was not the total amount of martensite, but its distribution, which was important in governing the ductility of the steel. Fatigue crack propagation has also in the past been studied in austenitic stainless steels ${ }^{10,11}$.

*e-mail: snevesmonteiro@gmail.com
In recent years, the effect of martensitic transformation on the strength and ductility of stainless steels subjected to cold plastic deformation under temperatures in the $M_{s}-M_{d}$ interval of metastability, continued to be investigated ${ }^{12-21}$. Gauss et al. ${ }^{12}$ found $78 \%$ of $\gamma$ martensite after $39 \%$ of plastic strain in AISI 201 steel. Pramanik et al. ${ }^{13}$ revealed the presence of strain-induced martensite during cold rolling of a duplex stainless steel. Hamada et al. ${ }^{14}$ indicated that in 201 and 201L steels strain-induced martensite is the dominant mechanism controlling the tensile flow and work hardening rate at temperature from $-80^{\circ} \mathrm{C}$ up to room temperature. Saha et al. ${ }^{15}$ reported that in a Nanoflex ${ }^{\mathrm{TM}}$ precipitation hardenable stainless steel the morphology of martensite formed in tension is different from that in shear deformation. Sheared samples show roundish precipitates with a core. Fan and $\mathrm{Fu}^{16}$ disclosed maximum value in the yield stress as consequence of martensite transformation in austenitic stainless steel subjected to severe plastic deformation. Kundu et al. ${ }^{17}$ investigated the room temperature tensile behavior of 304 stainless steel at strain rates from $5 \times 10^{-4}$ to $10^{-1} \mathrm{~s}^{-1}$. They verified a decrease in strength with increasing in strain rate, which was attributed to lesser amount of deformation-induced martensite. Taleb and Hauert ${ }^{18}$ showed that in $304 \mathrm{~L}$ steel the martensite nucleation takes place at the intersections between micro-shear bands or twins faults. Mertinger et al. ${ }^{19}$ emphasized that the nature of the strain-induced transformation is complex and probably associated with $\varepsilon$ phase and deformation twinning. Talonen and Hänninen ${ }^{20}$ emphasized the fact that the low stacking fault of metastable stainless steels is responsible 
for the strain-induced transformation involving the $\gamma$ and $\varepsilon$ phases. Spencer et al. ${ }^{21}$ found that a sufficiently high initial dislocation density is needed to localization of the martensite transformation in 304L and 316 L austenitic stainless steel as a Luders front. The martensite acts as an elastic reinforcing phase as it supports a higher stress than the austenite tensile loading even though the martensite co-deforms plastically with the austenite. Byun et al. ${ }^{22}$ investigated the work hardening dependence on the instability of several austenitic stainless steels, 304, 316 and 316LN. From room temperature until $-150^{\circ} \mathrm{C}$, the work hardening exhibits two stages consisting of a rapid decrease for small strains and an increase-decrease cycle before plastic instability occurs. TEM shows that twins and martensite along with dislocations are formed at subzero temperatures.

Martensite transformation was also investigated during fatigue tests in austenitic steels ${ }^{23-25}$. It was verified that under fatigue, crack growth is a non-uniform and very localized process due to the martensite transformation ${ }^{24}$. Furthermore, the crack growth rate is relatively slow owing to the intense hardening in the ahead plastic zone. This was related to the influence of martensitic transformation occurring near the crack tip ${ }^{25}$. In spite of all these research works, a comparison between a metastable and a strongly stable austenitic stainless steels would cast more information regarding the role played by martensitic transformation on the mechanical properties. Therefore, the present work compares the behavior of 302 , metastable, with that of 310 , stable, austenitic stainless steels.

\section{Experimental Procedure}

The austenitic stainless steels investigated were an AISI type 302 and AISI type 310 supplied by Sandvick. The chemical compositions of both steels are presented in Table 1 .

Both steels were received as hot-rolled bars with 10 $\mathrm{mm}$ in diameter. They were solution treated at $1100{ }^{\circ} \mathrm{C}$ for a complete annealed microstructure without residual phases except the face centered cubic (FCC) matrix. The average grain sizes were $31 \mu \mathrm{m}$ for 302 steel and $37 \mu \mathrm{m}$ for 310 steel. The annealed microstructure displayed a dispersion of round inclusions, apparently manganese sulfide, with some tendency to align along the longitudinal axis of the bars. Tensile specimens were machined to $4 \mathrm{~mm}$ of gage diameter and $20 \mathrm{~mm}$ of gage length as per ASTM standard ${ }^{26}$. Tensile tests were conducted in an Instron machine at temperatures of 25 , zero, -80 and $-196^{\circ} \mathrm{C}$ under a constant strain rate of 4.2 $\mathrm{x} 10^{-4} \mathrm{~s}^{-1}$. The amount of transformed martensite, vol\%, was detected throughout each specimen plastic deformation by means of magnetic balance. In type 302 steel no spontaneous transformation, without deformation, was detected at $-196^{\circ} \mathrm{C}$. This indicates that $\mathrm{M}_{\mathrm{s}}$ is below the liquid nitrogen temperature. Since strain-induced transformation was detected at $25^{\circ} \mathrm{C}$, the $\mathrm{M}_{\mathrm{d}}$ in 302 steel is certainly above this temperature. In 310 steel no strain-induced martensite was detected either by X-ray or magnetic balance at all testing temperatures. This indicates that both $\mathrm{M}_{\mathrm{s}}$ and $\mathrm{M}_{\mathrm{d}}$ should be below $-196^{\circ} \mathrm{C}$. Scanning electron microscopy (SEM) in a model Quanta FEG 205 FEI microscope was used to analyze the specimens fractured tips.

\section{Results and Discussion}

\subsection{Tensile Properties}

The true stress-true strain tension curves for both steels are shown in Fig. 1. At all investigated temperatures their ductilities measured by the strain at fracture are relatively higher ( $\geq 30 \%$ ), being always superior for the stable 310 steel below RT (room temperature). The highest ultimate strength was attained by the 302 steel at $77 \mathrm{~K}\left(-196^{\circ} \mathrm{C}\right)$ with more than $40 \%$ of ductility.

Owing to the martensitic transformation, a greater work hardening rate is developed above $4 \%$ strain in the 302 steel at all investigated temperatures. The typical variation of the work hardening rate $(\mathrm{d} \sigma / \mathrm{d} \varepsilon)$ with strain $(\varepsilon)$ in double log scale is exemplified in Fig. 2 for the $193 \mathrm{~K}\left(-80^{\circ} \mathrm{C}\right)$ test condition. In this figure the experimental points for 310 steel adjust well to a straight line indicating a Ludwik type of equation ${ }^{1}$ with $\mathrm{n} \sim 0.75$ along the whole tensile curve

$$
\mathrm{d} \sigma / \mathrm{d} \varepsilon=\mathrm{k} . \varepsilon^{\mathrm{n}}
$$

By contrast, for the 302 steel in Fig. 2 the points adjust to a linear relationship associated with $\mathrm{Eq}(1)$ with $\mathrm{n} \sim 0.4$ only up to $4 \%$ of true strain. Above this strain the value of $\mathrm{d} \sigma / \mathrm{d} \varepsilon$ raises significantly up to $20 \%$ of true strain and then falls abruptly until fracture. A similar behavior was reported by Byun et al. ${ }^{22}$ in 304 and 316 steels at subzero temperatures, where theses steels are also metastable.

\subsection{Martensitic Transformation}

The strain dependence of the volume fraction of deformation-induced martensite is shown in Fig. 3 for the metastable 302 steel. No magnetic response, which could indicate martensitic transformation, was obtained for 310 steel at any temperature. In Fig. 3 one should notice that the total amount of transformation occurred at $77 \mathrm{~K}\left(-196^{\circ} \mathrm{C}\right)$ with about $75 \mathrm{vol} \%$. At this temperature fracture, takes place

Table 1. Chemical composition (wt\%) of the investigated 302 and 310 austenitic stainless steels.

\begin{tabular}{lccccccccc}
\hline AISI Type & $\mathrm{C}$ & $\mathrm{Cr}$ & $\mathrm{Ni}$ & $\mathrm{Mo}$ & $\mathrm{Mn}$ & $\mathrm{Si}$ & $\mathrm{P}$ & $\mathrm{S}$ \\
\hline 302 (metastable) & 0.10 & 17.7 & 8.3 & 0.28 & 0.74 & 0.54 & 0.032 & 0.010 \\
310 (stable) & 0.09 & 25.8 & 19.1 & 0.30 & 1.84 & 0.41 & 0.024 & 0.018 \\
\hline
\end{tabular}




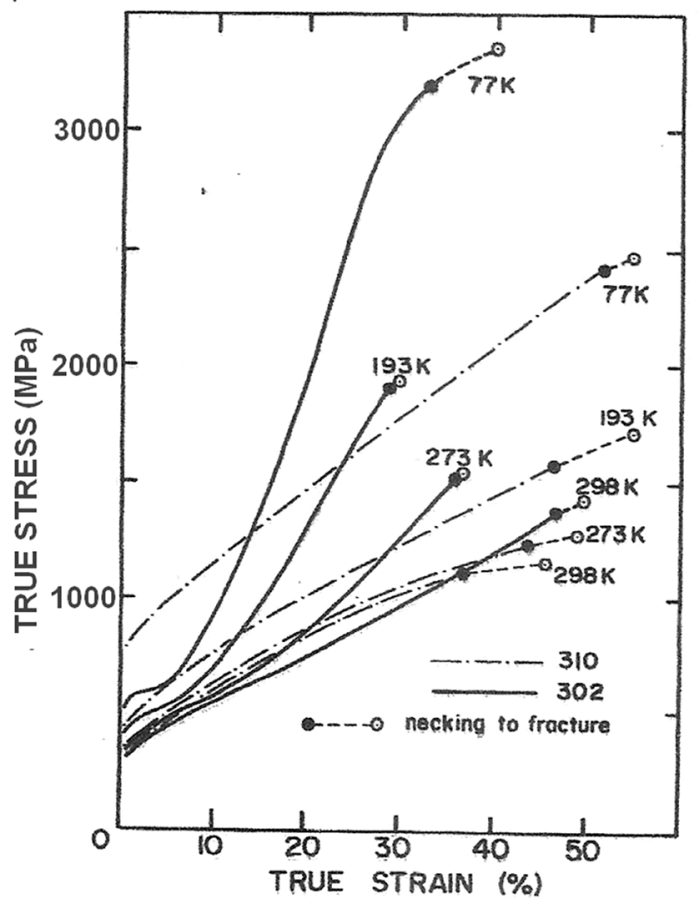

Figure 1. True stress-true strain tension curves for AISI types 302 and 310 stainless steels from $298 \mathrm{~K}$ (room temperature) to $77 \mathrm{~K}\left(-196^{\circ} \mathrm{C}\right)$.

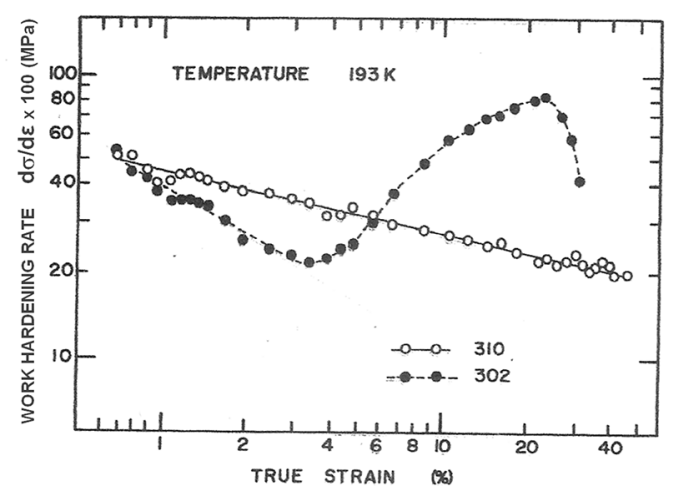

Figure 2. True strain dependence of the work hardening rate in double logarithmic for AISI types 302 1nd 310 stainless steels at $193 \mathrm{~K}\left(-80^{\circ} \mathrm{C}\right)$.

almost by an additional $10 \%$ in strain after the maximum load in the engineering curve. The reader should pay attention that the 302 steel true stress-true strain curve at $77 \mathrm{~K}$ (- 196 ${ }^{\circ} \mathrm{C}$ ) in Fig. 1 has a dashed segment of about $10 \%$ true strain corresponding to the decrease in load from ultimate strength to fracture in the engineering curve. This extension of the necking was earlier attributed to the amount of martensite ${ }^{7,8}$. Another point worth noticing in Fig. 3 is the minimum in ductility at $193 \mathrm{~K}\left(-80^{\circ} \mathrm{C}\right)$. The possible reason is that from this temperature and above, the amount of martensite at maximum load was still growing but could not reach a value

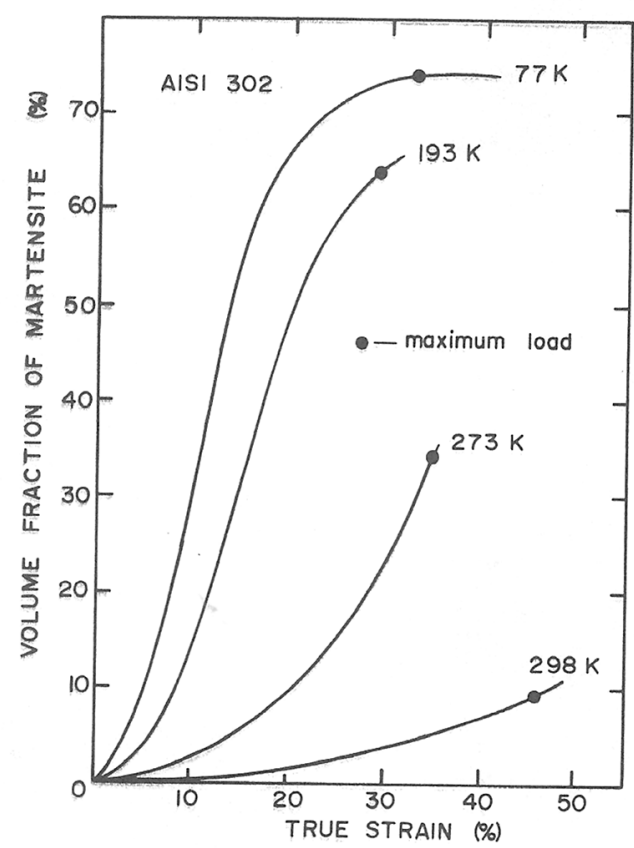

Figure 3. Variation of the amount (vol\%) of strain-induced martensite in AISI type 302 austenitic stainless steel.

sufficient to interfere with necking. Therefore, it could not extend the strain at fracture as happened at $77 \mathrm{~K}\left(-196^{\circ} \mathrm{C}\right)$.

\subsection{Fracture Modes}

In 310 steel the fracture surface at all investigated temperatures displayed a characteristic cup-and-cone appearance. The main mode of failure was opaque-transgranular, Fig. 4 , associated with dimples (microvoids) that are typical of a ductile type of fracture ${ }^{1}$. A dispersion of relatively larger microvoids containing inclusions (particles) is observed in the insert with high magnification. This ductile transgranular mode of fracture in 310 steel is associated with its relatively high ductility (45-55\%) displayed in Fig. 1, which is a wellknown property of stable austenitic stainless steels.

In 302 steel the fractured specimens at all investigated temperatures presented a generally, Fig. 5, bright-brittle and neckless appearance.

At $193 \mathrm{~K}\left(-80^{\circ} \mathrm{C}\right)$, the fracture surface was covered with craters formed at inclusions enveloped by packets of martensite laths, as shown in Fig. 6. These packets are, for the first time, reported as a specific mode of fracture in a metastable austenitic stainless steel.

In other metastable steels, such as TRIP $^{9}$, evidence exists of stress-assisted martensite at lower temperatures in association with banding due to large martensite plates. Here, the fracture mode in 302 steel were always related to relatively thin laths (lamellae) typical of deformation-induced martensite. Despite the brittle fracture appearance, Fig. 5, the moderate ductility (30-45\%) shown in Fig. 1 indicates 

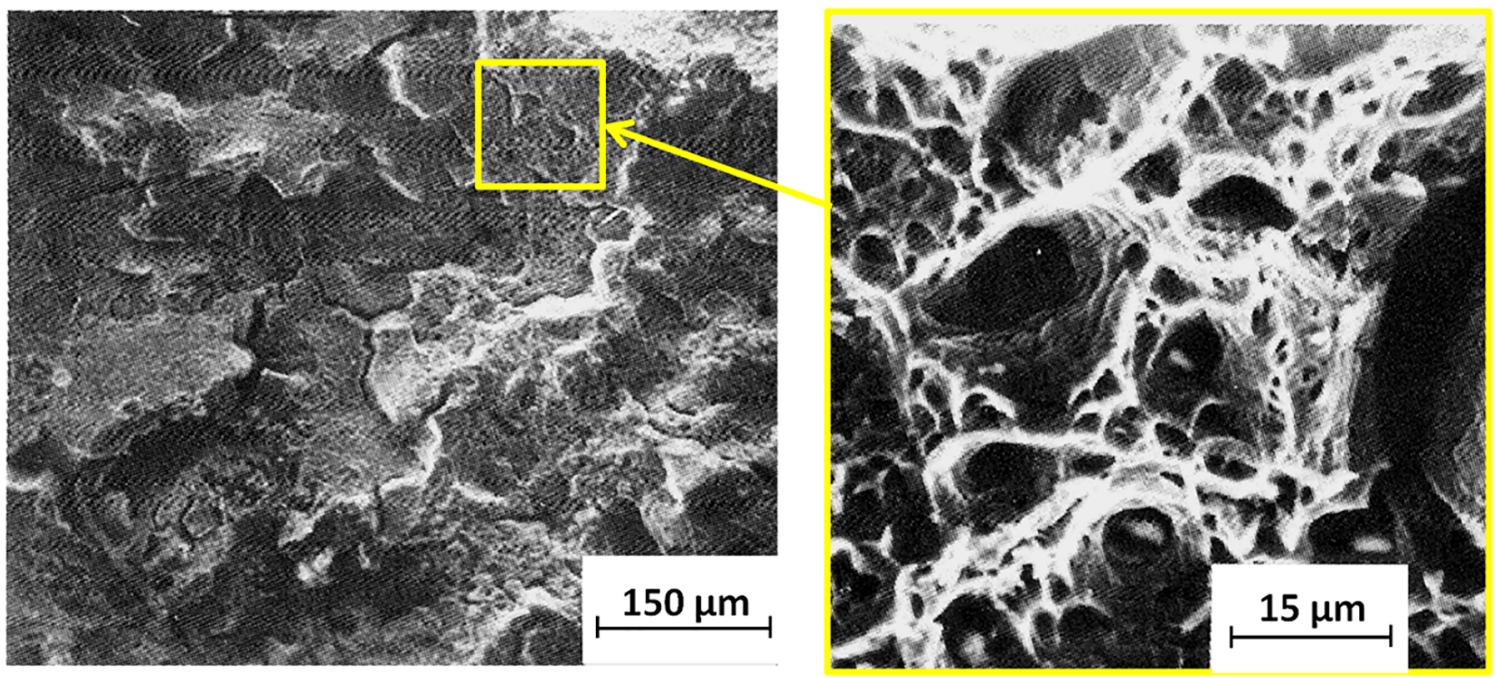

Figure 4. SEM fractographs of AISI type 310 stable austenitic stainless steel rupture at $77 \mathrm{~K}\left(-196^{\circ} \mathrm{C}\right)$.
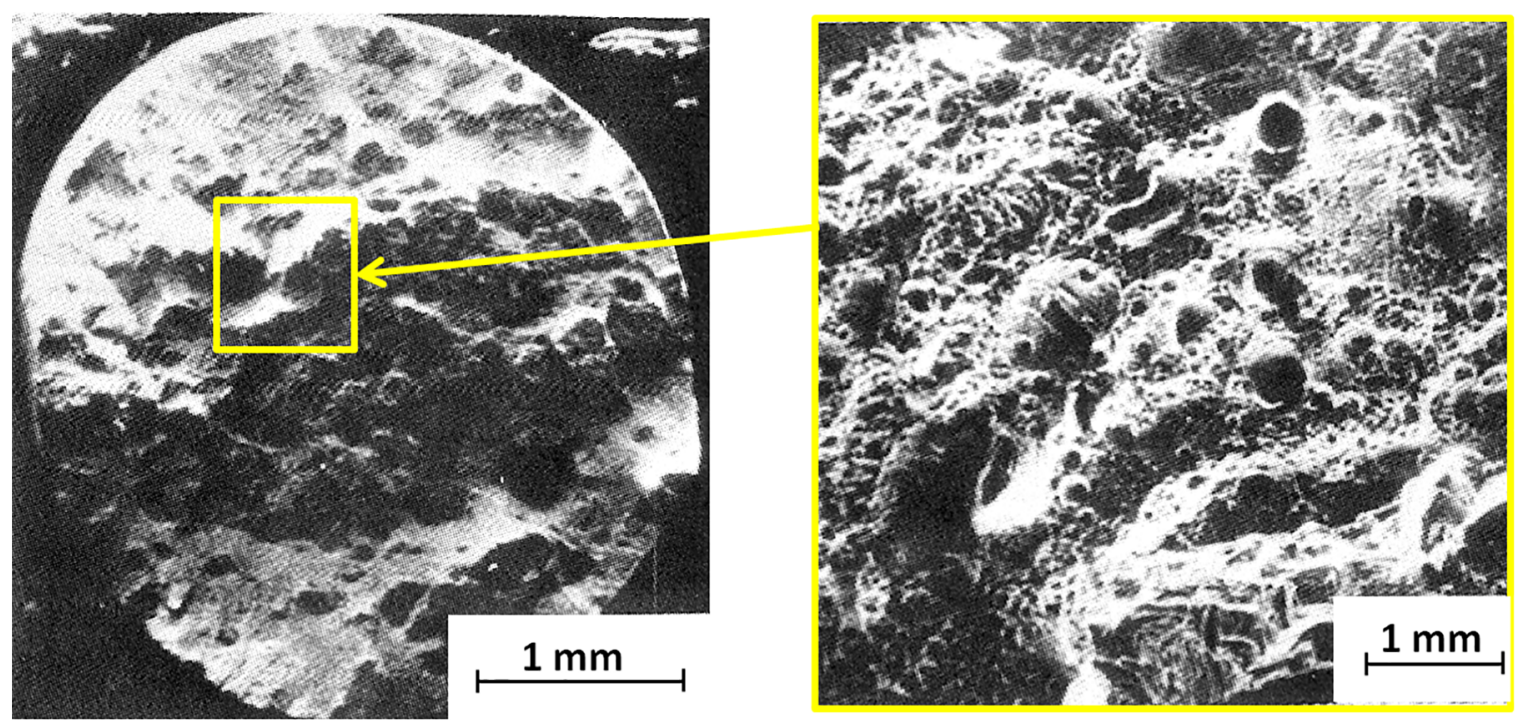

Figure 5. SEM fractographs of AISI type 302 austenitic stainless steel ruptured at $77 \mathrm{~K}\left(-196^{\circ} \mathrm{C}\right)$. General view.

a positive effect of the martensitic transformation on the mechanical properties. At $77 \mathrm{~K}\left(-196^{\circ} \mathrm{C}\right)$ where a high amount of martensite ( $75 \mathrm{wt} \%)$ was transformed, failure appeared to be also associated with cracks developed directly at martensite lamellae without participation of inclusions, as shown in Fig. 7. This could be another fracture mode characteristic of a metastable austenitic stainless steel, such as 302 in the present work, subjected to higher amounts of strain-induced martensite.

\section{Final Remarks}

The SEM fractographic results in Figs. 4 to 7 have shown that there is a considerable difference between the modes of fracture of a stable, 310 and a metastable 302 austenitic stainless steels. To some extent, this is surprising since both steels display about the same elongation at fracture, Fig. 1, particularly at $298 \mathrm{~K}\left(25^{\circ} \mathrm{C}\right)$. As for the fracture modes, the 310 steel failed at all investigated temperatures in a ductile fashion. This is apparently a consequence of the uniform decrease of work hardening, Fig. 2, with a relatively high (n $\sim 0.75$ ) exponent. Dimples and microvoids with inclusions, Fig. 4, are characteristics of this ductile mode. By contrast, the brittle and neckless fracture of 302 steel, Fig. 5, in association with a moderate level of ductility (30-45\%), Fig. 1, indicates a significant influence of martensitic transformation on its modes of fracture. Indeed, not only the transformation rate $(\mathrm{dV} / \mathrm{d} \varepsilon)$, Fig. 3, but also the amount and distribution of martensite, Figs. 6 and 7, are responsible for the increase in work hardening rate, $\mathrm{d} \sigma / \mathrm{d} \varepsilon$, Fig. 2, above 

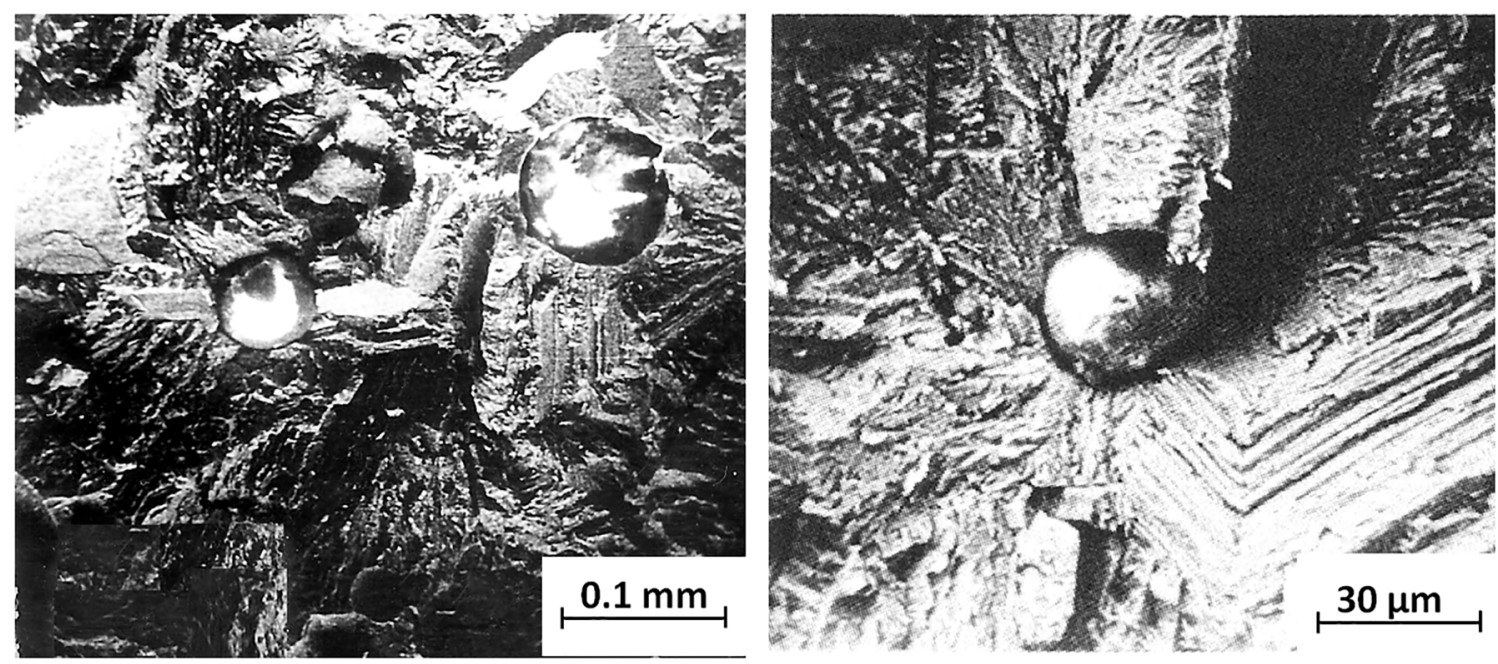

Figure 6. SEM fractographs of AISI type 302 austenitic stainless steel ruptured at $193 \mathrm{~K}\left(-80^{\circ} \mathrm{C}\right)$.
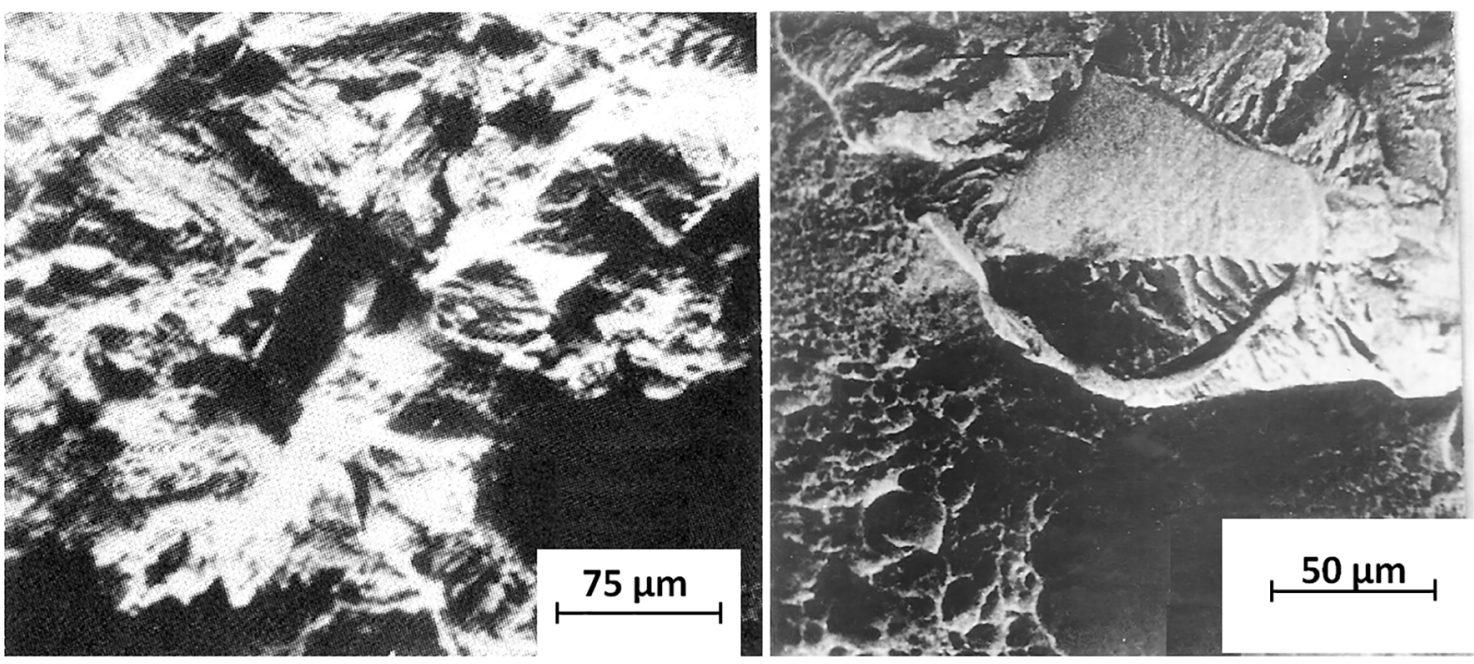

Figure 7. SEM fractographs of AISI type 302 austenitic stainless steel ruptured at $77 \mathrm{~K}\left(-196^{\circ} \mathrm{C}\right)$ showing details of the martensite fracture mode with different magnifications.

$4 \%$ strain, which increases the necking occurrence due to Considère's criterion ${ }^{1}$

$$
\mathrm{d} \sigma / \mathrm{d} \varepsilon \equiv \varepsilon
$$

The specific $\mathrm{dV} / \mathrm{d} \varepsilon$ at the beginning of necking for each temperature led to the differences in fracture mode. At $77 \mathrm{~K}$ $\left.-196^{\circ} \mathrm{C}\right)$ the transformation had reached an almost saturated condition and $\mathrm{dV} / \mathrm{d} \varepsilon$ is close to zero. A greater amount (75 $\mathrm{vol} \%$ ) of martensite is transformed. The fracture mode is mostly associated with cracks nucleated at crossing of martensite lamellae, as shown in Fig. 7. Above this temperature, the value of $d V / d \varepsilon$ is relatively high at maximum load, Fig. 3, and martensite is formed around inclusions, as shown in Fig. 6. In other words, the strain-induced martensite laths nucleate around inclusions accounts for the packets in Fig. 6. In this case, micro-cracks caused by the decohesion of the martensite interfaces with the FCC austenitic matrix, appears to be the fracture mode. Finally, the complex nature of the deformation-induced martensitic transformation ${ }^{19}$ demands a specific analysis of stresses and strains developed during necking to enable a precise characterization of the fracture mode at each temperature of a metastable austenitic stainless steel.

\section{Conclusions}

- $\quad$ Fracture modes of metastable austenitic stainless steels such as AISI type 302, which suffers martensitic transformation at room temperature (RT) and below 
may differ depending on the rate and amount of transformation.

- At $77 \mathrm{~K}\left(-196^{\circ} \mathrm{C}\right)$ transformation in 302 steel is already saturated when maximum load is reached. The amount of strain-induced martensite is high, 75 vol\%, and the fracture mode appears to be caused by cracks nucleated at crossing of martensite laths or lamellae.

- Above $77 \mathrm{~K}$ up to room temperature the transformation rate is high at the maximum load despite a comparatively lower amount. Martensite is formed as packets around inclusions. The fracture mode is associated with cracks caused by decohesion of the martensite/austenite interface.

- On the contrary, the fracture mode of stable austenitic stainless steel, such as AISI type 310 , without transformation from RT down to $77 \mathrm{~K}$, is typically ductile covered with dimples as well as microvoids filled with inclusions. Both steels, metastable and stable, for these different reasons present relatively high ductilities, together with elevated ultimate strengths.

\section{Acknowledgements}

The authors thank the support to this investigation by the Brazilian agencies: CNPq, CAPES and FAPERJ.

\section{References}

1. Meyers MA, Chawla KK. Mechanical Behavior of Materials. $2^{\text {nd }}$ ed. Cambridge: Cambridge University Press; 2009.

2. Zackay VF, Parker ER, Fahr D, Busch R. The enhancement of ductility in high strength steels. Transactions of the ASM. 1967;60:252-259.

3. Chanani GR, Zackay VF, Parker ER. Tensile properties of 0.05 to 0.20 Pct C TRIP steels. Metallurgical Transactions. 1971;2(1):133-139.

4. Gerberich WW, Hemmings PL, Zackay VF. Fracture and fractography of metastable austenites. Metallurgical Transactions. 1971;2(8):2243-2253.

5. Bandhakar D, Zackay VF, Parker ER. Stability and mechanical properties of some metastable austenitic steels. Metallurgical Transactions. 1972;3(10):2619-2631 .

6. Fahr D. Stress- and strain-induced formation of martensite and its effects on strength and ductility of metastable austenitic stainless steels. Metallurgical Transactions. 1971;2(7):18831892.

7. Bressanelli JP, Moskowitz A. Effects of strain rate, temperature and composition on tensile properties of metastable austenitic stainless steel. Transactions of the ASM. 1966;59:223-239.

8. Rosen A, Jago R, Kjer T. Tensile properties of metastable stainless steels. Journal of Materials Science. 1972;7(8):870876.
9. Maxwell PC. Fractography of several metastable Fe-Ni-C alloys. Metallography. 1976;9(1):9-31.

10. Bathias C, Pelloux RM. Fatigue crack propagation in martensitic and austenitic steels. Metallurgical Transactions. 1973;4(5):12651273 .

11. Pineau AG, Pelloux RM. Influence of strain-induced martensitic transformations on fatigue crack growth rates in stainless steels. Metallurgical Transactions. 1974;5(5):1103-1112.

12. Gauss C, Souza Filho IR, Sandim MJR, Suzuki PA, Ramirez AJ, Sandim HRZ. In situ synchrotron X-ray evaluation of strain-induced martensite in AISI 201 austenitic stainless steel during tensile testing. Materials Science and Engineering: A 2016;651:507-516.

13. Pramanik S, Bera S, Ghosh SK. Influence of Cold Rolling on Microstructural Evolution in 2205 Duplex Stainless Steel. Steel Research International. 2014;85(5):776-783.

14. Hamada AS, Karjalainen LP, Misra RDK, Talonen J. Contribution of deformation mechanisms to strength and ductility in two Cr-Mn grade austenitic stainless steels. Materials Science and Engineering: A. 2013;559:336-344.

15. Saha S, Datta K, Mitra MK, Lindgren LE, Post J. Any effect of processing history on precipitation hardening of metastable austenitic stainless steels. Key Engineering Materials. 2012;504506:851-856

16. Fan J, Fu T. Toughned austenitic stainless steel by surface severe plastic deformation. Materials Science and Engineering: A. 2012;552:359-363.

17. Kundu A, Chakraborti PC. Effect of strain rate on quasistatic tensile flow behavior of solution annealed 304 austenitic stainless steel at room temperature. Journal of Materials Science. 2010;45(20):5482-5489.

18. Taleb L, Hauet A. Multiscale experimental investigations about the cyclic behavior of the 304L SS. International Journal of Plasticity. 2009;25(7):1359-1385.

19. Mertinger V, Nagy E, Tranta F, Sólyom J. Strain-induced martensitic transformation in textured austenitic stainless steels. Materials Science and Engineering: A. 2008;481-482:718-722.

20. Talonen J, Hänninen H. Formation of shear bands and straininduced martensite during plastic deformation of metastable austenitic stainless steels. Acta Materialia. 2007;55(18):61086118 .

21. Spencer K, Embury JD, Conlon KT, Véron M, Bréchet Y. Strengthening via the formation of strain-induced martensite in stainless steels. Materials Science and Engineering: A. 2004;387-389:873-881.

22. Byun TS, Hashimoto N, Farrell K. Temperature dependence of strain hardening and plastic instability behavior in austenitic stainless steels. Acta Materialia. 2004;52(13):3889-3899.

23. Lehnhoff GR, Findley KO. The martensitic transformation and strain-hardening behavior of austenitic steels during fatigue and tensile loading. JOM. 2014;66(5):756-764.

24. Mine Y, Orita A, Murakami K, Olive JM. Fatigue crack growth behaviour in austenitic stainless steels subjected to superficial and entire hydrogenation. Materials Science and Engineering. A. 2012;548:118-125. 
25. Stolarz J, Baffie N, Magnin T. Fatigue short crack behavior in metastable austenitic stainless steels with different grain sizes. Materials Science and Engineering: A. 2001;319-321:521-526.
26. ASTM International. E8/E8M-152a - Standard Methods for Tension Testing in Metallic Materials. West Conshohocken: ASTM International; 2015. 